Article

\title{
Circular and Flexible Infill Concepts: Integration of the Residential User Perspective
}

\author{
Bob Geldermans * , Martin Tenpierik $(\mathbb{D}$ and Peter Luscuere \\ Department of Architectural Engineering and Technology, Delft University of Technology, \\ 2628 BL Delft, The Netherlands; M.J.Tenpierik@tudelft.nl (M.T.); P.G.Luscuere@tudelft.nl (P.L.) \\ * Correspondence: r.j.geldermans@tudelft.nl; Tel.: +31-628-287-283
}

Received: 27 November 2018; Accepted: 2 January 2019; Published: 7 January 2019

check for updates

\begin{abstract}
Circular building has gained considerable attention in the Netherlands during the past decade. It is rooted in concepts such as circular economy (CE) and Cradle-to-Cradle $\left(C 2 \mathrm{C}^{\circledR}\right)$, accentuating the closing and coupling of material loops to establish effective and efficient resource flows. Moreover, those concepts adhere to a systemic, holistic worldview, incorporating multiple flows and values. Although social aspects, such as health, wellbeing, and social inclusiveness, are generally part of circular building principles, specific benefits for end-users are not. This paper explores the synergistic potential of circular and flexible (Circ-Flex) criteria from the perspective of enhanced control and convenience for residents. The hypothesis is that without integrating the user domain, replicability of circular building concepts on a larger residential scale cannot be done in a truly sustainable manner. The paper is structured around two objectives: (1) further identifying the relationship between flexible and circular building; and (2) exploring the impact of circular, flexible building concepts and practices for the users of multi-family housing, specifically regarding interior partitioning. The research follows a mixed-mode methodology comprising of literature review, case study, expert consultations and a quick-scan assessment. Eleven Circ-Flex criteria are explored, grouped in three categories: flexibility capacity, circularity capacity, and user capacity. These criteria are applied to two partitioning variants, whilst exploring the performance regarding material circulation and user benefits.
\end{abstract}

Keywords: circular building; flexible building; user integration; materials; circular economy; sustainable housing

\section{Introduction}

Circular building is a building approach that has gained considerable attention during the past decade. It is rooted in concepts such as circular economy (CE), Cradle-to-Cradle (C2C), blue economy, and regenerative design, accentuating the closing and coupling of material loops in order to establish effective and efficient resource flows. Moreover, those concepts adhere to a systemic, holistic worldview, incorporating multiple flows and values. The Netherlands has tested the grounds for circular building practices for several years now, leading to state-of-the-art examples, such as the Town hall in Brummen (Architect: RAU, completed 2013), Patch22 in Amsterdam (Architect: Frantzen, completed 2014), the Venlo City Hall (Architect: Kraaijvanger, completed 2016), De Ceuvel (Architects: Space and Matter and DELVA, started 2012), and Circl (Architect: ArchitectenCIE, completed 2017). An important aspect these projects have in common is the distinction between structural and non-structural parts. This distinction facilitates circular flows of materials and products, whilst complying with the basic principles of flexible building. Flexible building accommodates changing spatial configurations in anticipation of changing occupant behavior, adding different users, functions, and potential upgrades to the equation. As such, a clear connection can be detected between flexible building (FB) principles 
and circular building (CB) principles. Additionally, structural and non-structural parts may represent different decision domains, for example: an investor regarding the structural base-building versus a user regarding the non-structural infill. Definitions for FB and CB adhered to in this paper are:

- Flexible building is a building (noun) or building activity (verb) designed to allow easy rearrangement of infill components, whilst accommodating the potentially changing needs of occupants.

- Circular building (verb) is the dynamic total of associated processes, materials and stakeholders that accommodate circular flows of building materials and products at optimal rates and utilities. A circular building (noun) is the manifestation of this in a temporary configuration.

Dutch CB initiatives have not yet ushered in a large-scale implementation of CB concepts in the Dutch construction practice. The call for bringing $\mathrm{CB}$ to scale, however, is resonating on Dutch political agendas e.g., [1-5]. In order to comply with those ambitions, the CB focus needs to shift from singular pilot projects for frontrunners to larger scale, replicable implementation strategies for the majority. This is only possible through a close collaboration of key stakeholders. The Dutch building sector at large, however, insufficiently includes a primary stakeholder: the end user of buildings [6,7]. When hinting at measurable added value, more comprehensive user-centric approaches are required. The authors advocate that the identification, application, and evaluation of criteria to measure user-benefits of $C B$ are essential next steps in this development. Among major target groups are inhabitants of multi-family residential buildings: a main typology in the denser urban areas of the Netherlands, only expected to increase in importance due to the growing need for housing in the coming decades e.g., [8,9].

Although social aspects, such as health, wellbeing, and social inclusiveness are generally part of circular building principles, specific benefits for end-users less so. This paper explores the synergistic potential of flexible and circular design principles from the perspective of user benefits, in terms of enhanced control and convenience for residents. The underlying hypothesis behind this study is that without integrating the user domain, replicability of circular building concepts on the larger-residential—scale cannot be done in a truly sustainable manner. The paper is structured around two objectives: (1) further identifying the relationship between flexible and circular building; and (2) exploring the impact of circular, flexible building concepts and practices for the users of multi-family housing regarding interior partitioning. By means of a mixed-mode methodology we aim to gain more insight into the existing gap in research and design, whilst providing a tool for deploying a more user-inclusive approach to the circular building development.

\section{Methods}

The research comprises an iterative mixed-mode methodology based on literature, case study, expert consultations and quick-scan assessment. The methodology adheres to design research approaches, as addressed in e.g., Blessing and Chakrabarti 2009, Mahmoodi 2001, and Attia 2018, focusing on the complexity of design, be it in general sense or specifically in relation to architecture and/or sustainability [10-12]. Aforementioned complexity is inherent to the dynamic and non-linear relationship between research, on the one hand, and design, on the other. Blessing states that design requires not only knowledge of the stakeholder goals and the product, but also about its life cycle i.e., how it is to be produced, transported, installed, used, maintained, and repurposed [10]. Improving design processes is thus not a matter of straightforward research activities. To implement improvements effectively, it is deemed vital to apply knowledge from various sources. This is not least applicable to the new field of circular and user-inclusive building. We explore precedent research in multiple domains and combine it with case study findings and input from experts. Not as a comprehensive overview, but as a means to integrate perspectives.

In Section 3, a literature study is reported regarding housing quality, as perceived by the user, as well as specifications of - and connections between-flexible and circular building. Key search terms applied are: 'Housing Quality', 'Open Building', 'Adaptable Building', 'Flexible Building', 'Circular 
Built Environments', and 'Building Performance Evaluation', particularly in the context of Dutch multi-family housing. These terms were applied separately and in combinations.

The research gap regarding circular and flexible building performance in relation to the building occupants necessitates the conduction of additional case-study research and expert consultations (Section 4). Three cases are selected to look at change and flexibility of the interior floor plan from a user perspective: Molenvliet, The Netherlands; Kodan Experimental-housing Project, and the Century Housing System, Japan; and Bostadsrättsförening, Sweden. Furthermore, multiple experts are consulted to further investigate linkages between circularity, flexibility, and user benefits. The experts are associated with the National Renovation Platform (NRP); the Amsterdam Institute for Advanced Metropolitan Solutions (AMS), more particularly relating the projects Smart Urban Retrofitting (SUR) and Circular Components in the Built Environment (CCBE); and Open Building Design (OBD), all based in The Netherlands. Input is sourced during multiple face-to-face meetings, of on average 45-60 min, with the chairman of NRP, the founder of OBD, and the program managers of SUR and CCBE. These expert consultations were intentionally unstructured in order to allow for new, unforeseen aspects to come into view. The combination of those experts safeguarded a welcomed level of intersubjectivity.

Based on the literature, case study and expert consultations, a basic set of criteria is selected (Section 5) for conducting a comparative quick scan of two indoor partitioning variants: a traditional one and its circular and flexible (Circ-Flex) counterpart. In this quick scan, circularity, flexibility, and user perspectives are integrated.

Finally, in Section 6, the results and methodology are discussed from various vantage points, in particular institutional context, legal framework, culture, and demography.

The diagram of Figure 1 displays the research structure and methods.

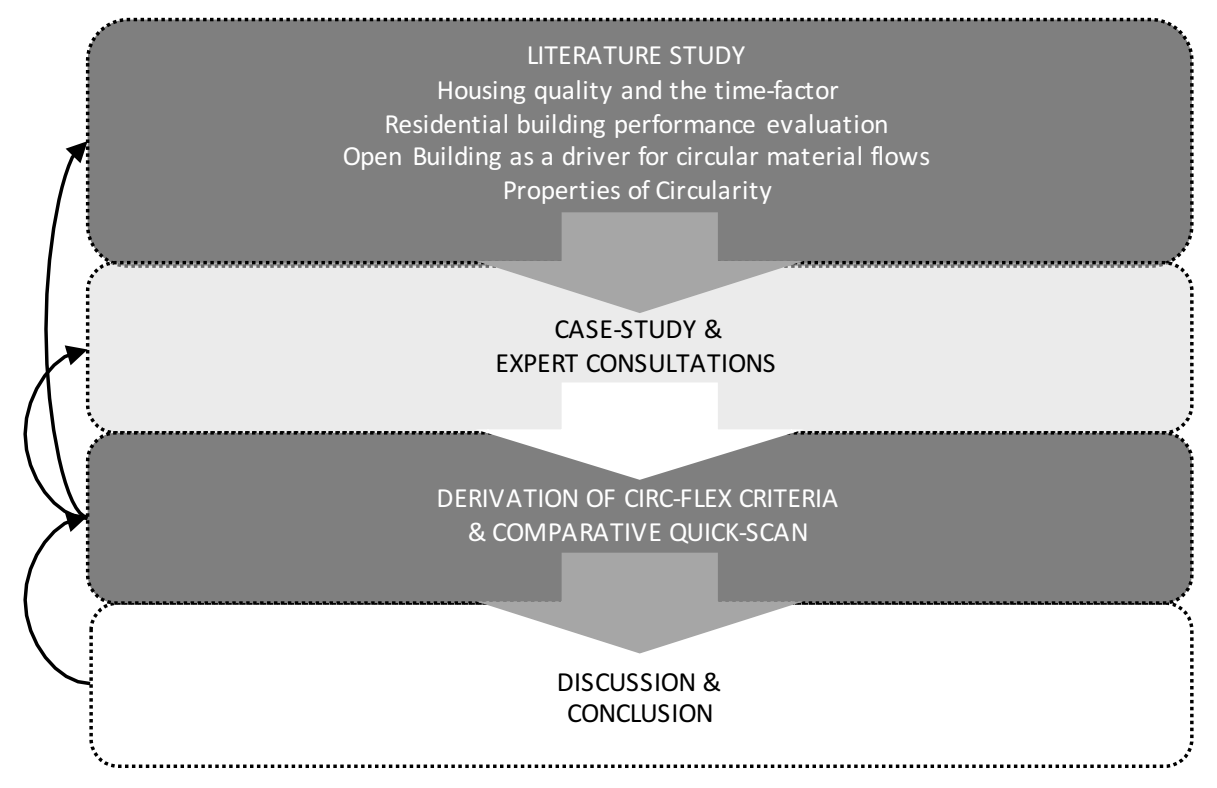

Figure 1. Research structure and methods.

\section{Delineation}

The Dutch context is of primary concern in this research, whilst exploring examples and lessons learned in other countries as well. Furthermore, the focus is on multi-family housing, being a primary typology in densely populated areas such as the Randstad (home to approximately 7 million people, in the western part of the Netherlands, including the cities of Amsterdam, Rotterdam, The Hague, and Utrecht), see Figure 2. Social housing plays an important role in this respect. In the Netherlands, social housing corporations own $33 \%$ of the housing stock (of which the majority is multi-family). In the Randstad, this number is higher, peaking at $40-45 \%$ in Amsterdam and Rotterdam. 


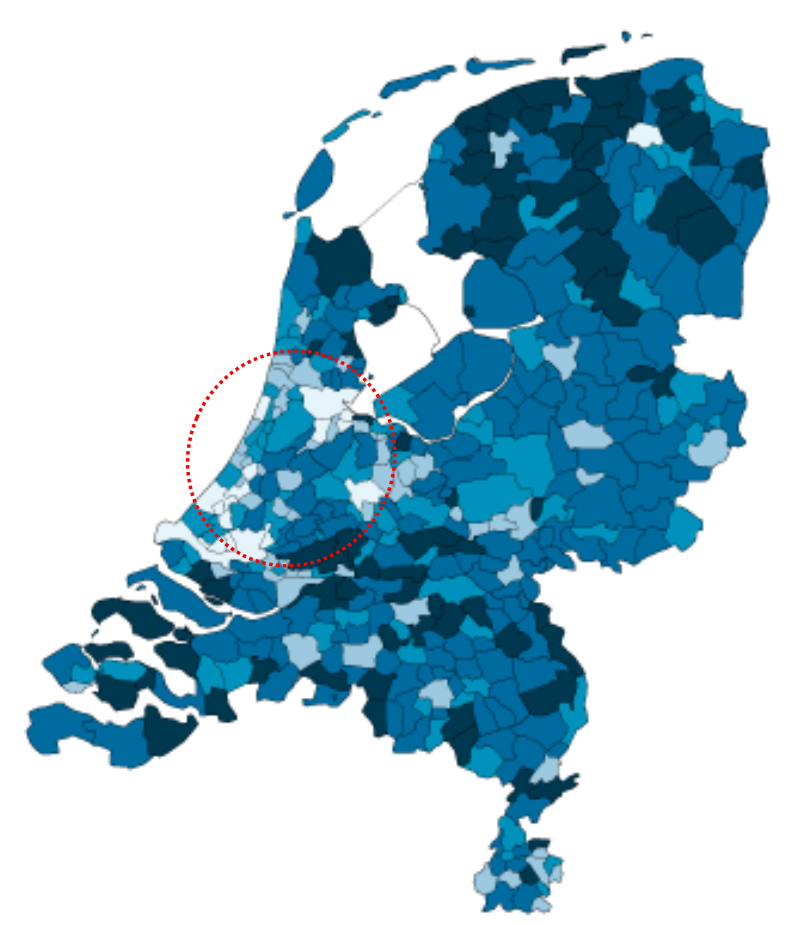

Multi-family homes

in the Netherlands

More than $50 \%$

$30-50 \%$

$20-30 \%$

$10-20 \%$

Less than $10 \%$

Figure 2. Share of multi-family homes in the Netherlands with Randstad encircled in red [source: CBS].

\section{Literature Study}

This chapter is allocated to a concise literature study. Starting point (addressed in Section 3.1) is the notion of housing quality over time, whilst anticipating yet unknown users and use patterns. Subsequently, the focus is on Building performance evaluation (Section 3.2), Open Building as a driver for circular material flows (Section 3.3), and properties of circularity (Section 3.3).

\subsection{Housing Quality and the Time-Factor}

When articulating the importance of buildings in general, and our homes in particular, one could take multiple approaches. From a predominantly objective and technical viewpoint: homes provide us with shelter and protect us from the external environment, and as a result we spend the majority of our time in them [13]. Related, but more subjective and complex, would be a description of the extent to which we feel 'at ease' in our home. This touches upon the experience of safety, comfort, and joy, or any other emotion strived for. A more philosophical pondering could lead to the description that "we depend on our surroundings obliquely to embody the moods and ideas we respect and then to remind us of them" [14].

The importance of individual identities, within the potentially overwhelming collectiveness of a city, becomes most tangible inside of people's homes. This is where diversity thrives. However, developers, authorities, designers and builders have experienced difficulties in internalizing that notion of diversity e.g., [15-17]. Habraken based many of his publications on this 'system failure' of blending collective (the base-building or support) and individual domains (the fit-out or infill), specifically regarding the realization of mass housing e.g., [16,18-20]. He observes that: "zoning laws, building codes, enforceable design guidelines, or covenants [ ... ] increasingly replace direct negotiation in the creation of contemporary built environment. Nonetheless, controls, boundaries, and guidelines issued by governing authorities from the top down are a poor substitute for actual conversation between peers" ([20], page 9). Van der Werf points at the lack of acceptance of the distinction between collective and individual by fellow architects and developers in the Netherlands, especially when it concerns façade elements [21]. This statement was made in 1993, but is—to a major extent—still valid: even if the 'open building' discourse has evolved among peers in the architectural realm, key parties (developers, 
corporations, authorities, designers, engineers) in the Netherlands still find it hard to adjust their way of working, not least with regard to risks associated with personalized use and physical changes in the real estate e.g., [22-25]. Regardless of the nature of those risks, it implies a deeply ingrained inability to internalize 'dynamic user-behavior' in the design, development and management of real estate.

Observing trends and history of building practice in the Netherlands, and following the associated literature amongst others: $[17,20,26-38]$ at least three conclusions can be drawn regarding the extent to which multi-family housing in the Dutch context accommodates change over time:

1. Requirements of housing quality differ per person or target group as well as per time-period; the existing stock will always ask for adaptations,

2. Housing inflexibility is still the norm; the large majority of multi-family housing is designed with no or one single-type of-occupant/occupancy in mind,

3. Paradigm shifts, rooted in a desire for more flexibility, have been hinted at more than once in the last decades.

Straub and Vijverberg, 2004, for example, define housing quality as: "the physical characteristics of a dwelling, which are relevant to the use of that dwelling, including the plan features and facilities provided". ([32], page 2-3), whilst observing that the existing (social) housing stock does not sufficiently fulfill the changed - and changing-demand for more space, different space-plans, more quality, and freedom of choice in qualities [ibid.]. Boelhouwer et al. 2014 state that, on an individual level, there is hardly any freedom of choice for tenants of social housing, apart from a restricted right to "zelf aangebrachte voorzieningen' (self-added facilities), without any guarantee on the value of those interventions at the end of the contract-for owner or renter [35]. They conclude that freedom of choice is not going 'beyond exit', provided the housing market allows this [ibid]. Tummers 2016 highlights specific changing social conditions that are as unforeseen as they are decisive for new ways of living, hence new design perspectives, by focussing particularly on self-organization and co-housing in relation to the energy transition [38]. Even though the focus here is on a specific lifestyle and target group, it is indicative for the increasing resilience that is asked of the housing sector, disrupting outdated traditions in favor of new, more sustainable models.

\subsection{Residential Building Performance Evaluation}

If end-users of buildings are insufficiently engaged with the physical and functional development of their direct living environment, these environments are prone to lose the contact with their occupants to some degree, and subsequently fail to resonate their identities as well as a sense of community coherence. Here, we refer back to aforementioned insights of, for example, De Botton, Sanoff and Habraken $[14,16,17]$, but this also connects with more practical perspectives and studies from researchers and housing associations aiming to understand and serve basic housing behavior and fulfillment of people. For example, with regard to the Dutch housing market, Dogge and Smeets 2004 looked into the relationship between tenants' satisfaction and commitment [39].

Furthermore, post-occupancy evaluation (POE) has gained ample recognition as an important tool in both academic and applied settings [40,41], whilst addressing the often-occurring gap between designed and actual performance of buildings [42-44]. However, Hay et al. state: "there is little evidence that this body of research has transferred to the practice environment to close learning loops and ensure future projects are informed by a joined-up evidence base rather than the isolated experience of individual professionals" ([41], Page 2). Göçer et al. come to a similar conclusion stating that, although POE can help drive the building design and procurement process forward, " ... the findings do not seem to match the rhetoric; in other words, POE is not used effectively in practice." ([45], page 15).

Related to the fact that POE has not yet been effectively integrated in the design and construction practice, it is also still rather limited in its scope, with a large accent on quantitative energy performance and "narrow" surveys of satisfaction [41]. More fundamental questions about the sustainability of 
the built environment, dealing with e.g., robustness to secure future use and user behavior, are rarely addressed. Lessons could be learned from studies into consumer behavior. For example, concerning mental and behavioral response that precedes or follows user activities [46].

\subsection{Open Building as a Driver for Circular Material Flows}

An important commonality among the circular building examples mentioned in the introduction is the distinction between support and infill. This open building $(\mathrm{OB})$ approach accommodates changing spatial configurations, in anticipation of a dynamic, ever-changing user-behavior $[13,47,48]$. The time factor is thus included more prominently. By consequence, the chance increases that different functions and users-not necessarily predictable-are becoming part of the equation. At this point, we see a clear liaison between flexible building principles, on the one hand, and circular building principles on the other. Table 1 displays some general aspects regarding the distinction between support and infill domains, whilst advocating the need for adaptability, prominently on the infill side, and pinpointing the relation with circular principles [49].

Table 1. General aspects regarding the distinction between support and infill domains.

\begin{tabular}{|c|c|c|c|}
\hline \multirow{8}{*}{ 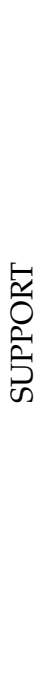 } & \multicolumn{2}{|r|}{ Characteristics } & \multirow{8}{*}{ 当 } \\
\hline & $\begin{array}{c}\text { Long lifespan } \\
\text { Fixed } \\
\text { Architecturally strong }\end{array}$ & $\begin{array}{l}\text { Short lifespan } \\
\text { Variable } \\
\text { Demountable }\end{array}$ & \\
\hline & \multicolumn{2}{|r|}{ Scope } & \\
\hline & $\begin{array}{l}\text { Main structure } \\
\text { Collective spaces }\end{array}$ & $\begin{array}{c}\text { Partitioning walls } \\
\text { Kitchen, bathroom } \\
\text { Mechanical, Electric, and Plumbing services } \\
\text { Possibly façade elements }\end{array}$ & \\
\hline & \multicolumn{2}{|r|}{ Decision Sphere } & \\
\hline & Investor & User & \\
\hline & \multicolumn{2}{|c|}{ Circularity Relation } & \\
\hline & $\begin{array}{l}\text { Retained or increased value } \\
\text { Long lifespan }\end{array}$ & $\begin{array}{l}\text { Adapts to change } \\
\text { Less waste } \\
\text { Facilitates circular reuse }\end{array}$ & \\
\hline
\end{tabular}

The distinction between support and infill is inextricably linked to the notion of diverging and changing interests at stake. Between investors and users on the one hand, and between current and future stakeholders (new investors, new users) on the other. Although base-buildings could, and sometimes should, be adaptable as well, the use(r)-flexibility predominantly manifests itself on the infill side, following social dynamics, as explained earlier. This leads to multiple infill material and product cycles during the existence of a building, which accommodates a more effective, bespoke, and up-to-date indoor materialization, opening up to new supply and service models that serve a circular economy (right below in Table 1). Such new models match with the ongoing "democratization" of building services, most prominently tangible in energy supply systems [50].

\subsection{Properties of Circularity}

Underlying study explicitly focuses on decision-making power regarding the individual, interior domain. The social benefit of this decision power is accompanied by a potential material benefit, provided that key (co-)design preconditions are respected. Geldermans and Rosen-Jacobson's 2015 position Circularity Potential in the combination of intrinsic properties (material and product characteristics) and relational properties (building design and use characteristics), see Figure 3 [37]. 


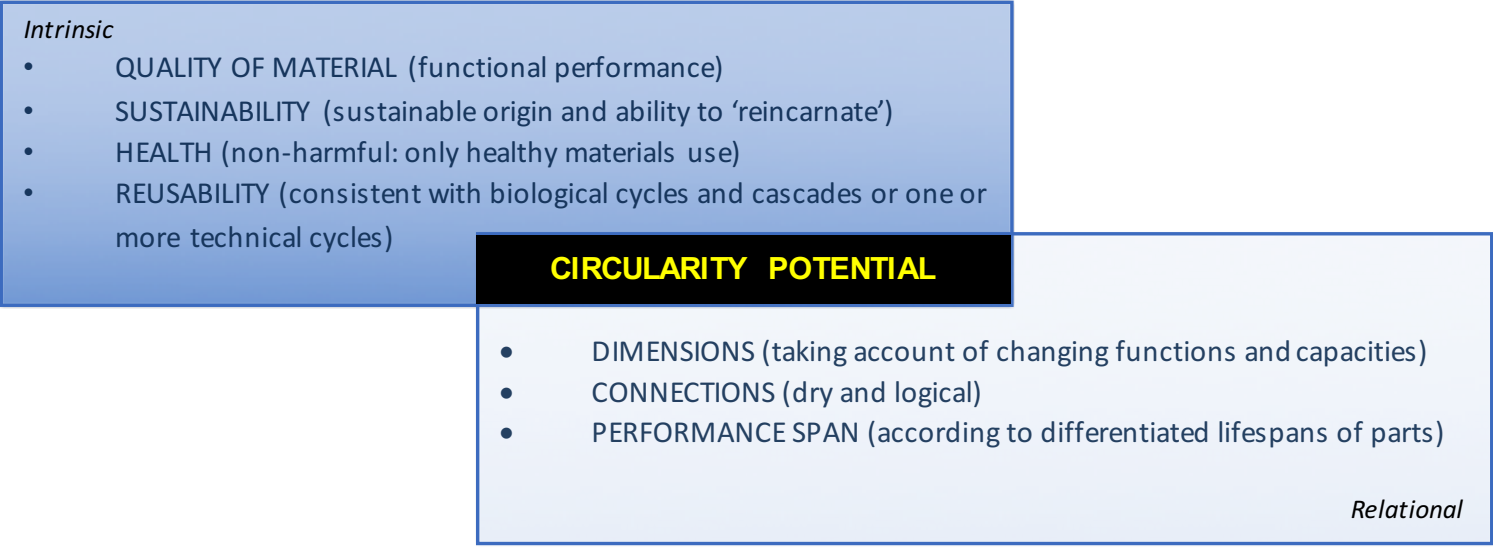

Figure 3. Relational and intrinsic properties of materials and products in circular building configurations.

If non-structural components can be changed to optimally match with the new requirements, it becomes easier to anticipate renewability routes for the redundant products and materials at the highest value and utility. Renewability refers to the use of resources that can be replenished at-at least-similar quality levels, and within appropriate time-scales, including energy, water, air, top soil, and materials [50]. Renewability is at the heart of the circular economy (CE) concept. The matrix of Figure 4 displays differentiated renewability routes for components, products and materials in a CE model, specifically with regard to partitioning walls. This matrix-based on Brand 1994 and Ellen MacArthur Foundation 2012, as adapted by Geldermans and Rosen-Jacobson 2015-focuses on technical and design specifications of products, pinpointing supply-chain routes and re-use value $[37,51,52]$. In order to optimally include user benefits into the equation, we need to better determine what those benefits are.

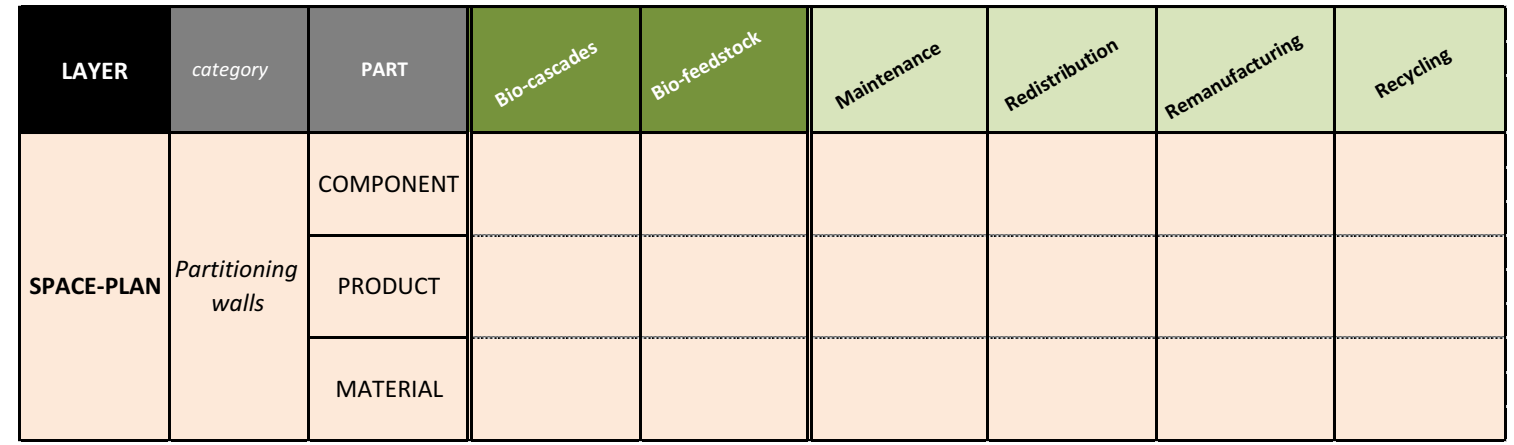

Figure 4. Differentiated renewability routes for components, products and materials in a circular economy (CE) model, specifically with regard to partitioning walls.

The aim for circular resource systems, as articulated in Dutch and European policy documents e.g., $[53,54]$ can thus contribute to providing leverage for bringing user centered Circ-Flex interventions to scale.

\section{Results from Case-Study and Expert Consultations}

\subsection{Lessons from Three Cases}

As stated in Section 3, thus far little research has been conducted to evaluate the performance of residential interior lay-outs as perceived by inhabitants. Several projects and associated studies, however, have provided valuable insights in this respect. Of particular interest to this paper are three projects, due to (1) their strong focus on flexibility as a value aspect for the user; and (2) their performance-monitoring schemes. After a brief description of each case, key findings are listed. 


\subsubsection{Molenvliet, Papendrecht, The Netherlands}

In the 1970s, architect Frans van der Werf introduced a new typology of high density housing in a low-rise fabric. The typology consisted of an infill-able base-building structure of parallel piers, floors, and roofs around courtyards, combining so called longitudinal and transversal support structures, and allowing free dwelling fit-outs for each user [22]. The Ministry of Housing nominated this typology 'Experimental', in order to understand how the regulatory framework limits the evolution of housing in the Netherlands. Housing association Papendrecht ordered this 'Experimental' design for 80 dwellings for rent. Van der Werf scheduled two private infill consultations of one hour with each of the users, following the routing of the building blocks on site. During the first meeting, spaces and functions were discussed, related to the ages, hobbies and preferences of each family member. After two weeks, a second meeting was held on confirmation or small changes and on details in kitchen and bathrooms [55]. In 2014, Shanshan Li performed a study on the interior lay-out changes in the Molenvliet project over time, interviewing fifteen households who had lived there between 1-38 years [56]. Eight out of fifteen had carried out renovations, six of which concerned modifications in the partitioning configuration.

Key lessons:

(1) The unique life experience of each of the users had to be valued, necessitating an unprejudiced design flow, without personal preferences of the architect,

(2) Hobbies of the users were as important as basic activities.

(3) From the renovations that were carried out by eight of fifteen households, six concerned modifications in the partitioning configuration.

4.1.2. The Kodan Experimental-housing Project (KEP) and Century Housing System (CHS), Tokyo, Japan

In the 1970s, the number of dwellings in Japan began to exceed the number of households, changing the aim of research and development from supplying a large number of homes to improving their quality and meeting diverse residential needs [57]. The Tsurumaki-3 housing estate of Tama New Town, Tokyo, was the first undertaking of the Kodan Experimental-housing Project (Japanese Housing Corporation). KEP started in 1973 in order to research and develop flexibility and adaptability for housing. Following this first initiative, the Ministry of Construction started the Century Housing System (CHS) as a government-led research initiative formed primarily by academic members in the early 1980s. The objective was to extend the longevity of housing by developing a systems approach to the housing sector that focused on "the changeability of components throughout the building life, reducing premature functional obsolescence by increasing the building's adaptability" ([58], page 1). This objective led to a system that distinguished five building component layers according to lifespan and economic rationality [ibid]. Wakiyama et al. 2000 studied how residents and managers recognized the CHS system and how it worked for them [59]. The study was conducted sixteen years after the initial occupancy. Minami 2010 and 2016 investigated for both KEP and CHS related housing projects how residents have adopted the design concepts to suit their individual needs, as well as the way in which they adapted their living environments to changes in their lifestyles over time by remodeling rooms and changing the position of partitions $[57,60]$.

Key lessons:

(1) In Japan, a main driver for moving to open, flexible buildings derives from an imminent labor shortage in the construction sector, making it more important to design and construct buildings which require less skilled labor, for example residents and users themselves.

(2) Respectively 51\% (unit design Type A) and 59\% (unit design Type B) of the surveyed residents with a KEP movable partitioning system changed the layout at least once (in 15-30 years), due to 
changes in lifestyle or family composition. Whereas this was $8 \%$ of the surveyed residents of a unit design Type $\mathrm{C}$ (non-movable partitioning).

(3) Out of a set of twenty characteristics that could influence a resident's decision to inhabit a particular housing unit of the CHS project, "easy to change layout" was chosen by $23 \%$ of the surveyed residents.

(4) The CHS system was perceived as too complex, which made residents shy away from exploring the potential in many cases. This led to a simplification that has been recognized by almost all in the Japanese industry, namely a simple division in a base-building domain and an infill domain.

\subsubsection{Bostadsrättsförening (BRF), Stockholm and Göteborg, Sweden}

Between 2001-2008, Bostadsrättsförening (BRF) Tenant-Owner association, built several multi-residential housing estates in Stockholm (BRF 1) and Goteborg (BRF 2-5), Sweden. All co-owned properties are situated in waterfront locations, where most of the local housing production was carried out during that period. An extensive report by Femenias et al. 2016 focused on these housing projects, in order to study internal renovations and home-makeover over time. The study aimed to provide insights into what residents appreciate, or are dissatisfied with, in their apartments, what changes they made, and the motivations behind it [61]. In 2015, a questionnaire was sent to all 462 households that reside in the five estates, with a response rate of $68 \%(=315)$. The questionnaire revealed that not only did the owners engage in renovation and redecoration of the apartments, which was presumed when initiating the study, they also rebuilt and reconstructed the apartments, which was not anticipated. The questionnaire gave insights into the amount and nature of renovations that the present owner-occupier had carried out in their apartment as well as of alterations they knew that former owners had done [61-63].

Key lessons:

(1) Residents are dissatisfied with, among others, a lack of storage facilities and work space, a lack of soundproofing between different rooms, the layout of the kitchen and bathroom, poor quality of materials, unused surface, and narrow and dark hallways

(2) Many renovations were (also) due to the fact that "the apartment has material and performance of low technical and aesthetic quality, and is therefore replaced earlier than normal maintenance" ([61], page 42).

(3) Overall, over $30 \%$ of the respondents in this study made changes to the floor plan layout.

(4) The findings did not indicate that the motivation to achieve a higher sales value was a direct motive for action. Instead, "increased value appears as a supporting argument to increase the standard or personalize" ([61], page 26).

\subsection{Expert Consultations}

Multiple expert consultations took place to further investigate the linkages between circularity, flexibility, and residential user benefits. The experts are associated with Open Building Design (OBD), National Renovation Platform (NRP), and the Amsterdam Institute for Advanced Metropolitan Solutions (AMS). OBD is a platform initiated by architect Frans van der Werf, based on the vision that in housing, residents should decide on the lay-out of their own dwelling. Frans van der Werf has applied open building principles in his own work as of the 1970s, one of which gained significant attention in recent years (project Molenvliet, see the case-study section), also in relation to circular building ambitions. NRP is an independent foundation striving for sustainable use of the building stock through renovation and transformation strategies. The notions of co-design, adaptable buildings and flexibility strongly resonate in these strategies. Ongoing projects on circular transformation of real estate in Amsterdam defined the expert-input, but also earlier practical experience of NRP's chairman in his position as housing developer. AMS is a knowledge institute, founded by Delft University of Technology (TUD), Massachusetts Institute of Technology (MIT) and Wageningen University and 
Research (WUR), with the aim to implement and test innovations in real urban settings. Two AMS projects in particular were relevant in the context of this paper: Smart Urban Retrofitting (SUR, project lead: WUR, Department of Social Sciences) and Circular Components in the Built Environment (CCBE, project lead: TUD, department of Management in the Built Environment). The former refers to the restructuring of existing housing stock in Amsterdam, involving e.g., informational flows, and actor relations. The latter concerns the development of a circular kitchen model, in co-creation between housing corporations, suppliers and knowledge institutes.

\subsubsection{Open Building Design}

Frans van der Werf of OBD endorses the statement that among the most important changes to the interior lay-out are addition and/or removal of indoor partitioning walls. In accordance with Christopher Alexander's Pattern Language 1977, this importance can be understood via three perspectives: effective use, social experience, and sense-making [64,65]. Firstly, partitioning divides spaces according to functional differentiation. Secondly, partitioning provides a base for distinct interior design. And thirdly, partitioning supports dynamic processes of change in the activity of living [65]. Virtually countless reconfiguration schemes in the interior lay-out are possible, without compromising fixed elements, such as mechanical, electrical, plumbing utilities and infrastructure. Van der Werf designed housing structures with flexible lay-out capacity in multiple projects, such as the Pelgromhof project in Zevenaar for example (1999-2001), see Figure 5a,b. Figure 5a shows the open plan, with only a fixed shaft for technical services, and Figure $5 b$ shows user consultation in a real size model, where infill components could be positioned on a modular $30 \mathrm{~cm}$ grid. Van der Werf indicates that the interaction with the residents, as of the initial stage, is labor-intensive but rewarding. It does justice to the fact that all households are different, and personalization needs to be respected in the design and materialization of individual housing units.

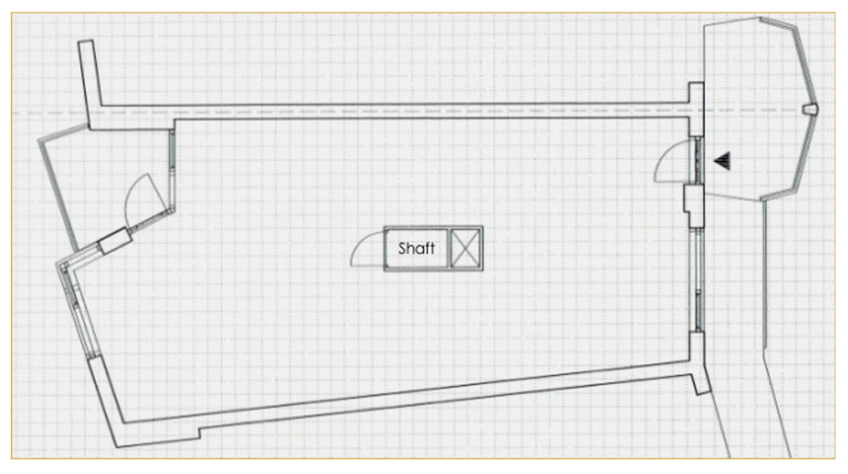

(a)

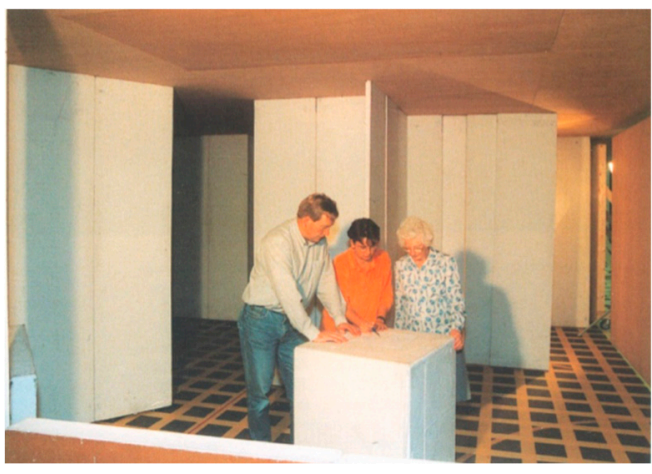

(b)

Figure 5. Open plan design (a) and user consultation (b) concerning Pelgromhof project, Zevenaar, The Netherlands, Frans van der Werf 1999-2001 (Copyright: Frans van der Werf).

\subsubsection{National Renovation Platform}

The reasons behind alterations in the lay-out may range from longer lasting arguments, such as increase or decrease in family size, to quicker passing ones, such as lifestyle changes. But there are many more arguments imaginable that would drive modification of the space-plan. Key is the user's control to modify the interior layout by changing partitioning configurations, in any way he or she wants. This social aspect of the Open Building concept has always been at the heart of the National Renovation Platform (NRP). NRP keeps a close eye on social and demographic phenomena and how that relates to the quality and quantity of largely already existing real estate. NRP underscores the importance of new collaborations between stakeholders when collective and individual domains are separated. Moreover, this separation also requires new ways of financing, linked to the material and 
technical divisions. New ownership configurations will emerge, in which the user has full control over the infill. This represents a value, provided that the next user of the space has the same level of control [66]. Which does not mean the user should necessarily own the infill components: ownership can also be outsourced to suppliers or other external parties. Aforementioned considerations are closely connected to the extent to which circularity of products and materials can be established and managed.

\subsubsection{Amsterdam Institute for Advanced Metropolitan Solutions}

The fact that change is rarely accommodated in housing design and development also resonated in the Smart Urban Retrofitting project (AMS/WUR). Most of all with regard to the interaction and mutual understanding between key stakeholders in the Amsterdam housing sector, notably housing corporations and social housing residents. A deep communication gap made it hard for housing corporations to implement upgrades to the housing stock. Although this project concerned energetic behavior and interventions, rather than layout alterations, the lack of appropriate communication is estimated to be indicative of the sector's culture, forming a barrier for residents-engagement. It was found that bottom-up strategies, such as co-creation and community participation, are crucial and necessary institutional aspects of urban retrofitting, even if it could potentially slow-down the decision-making process [23].

The Circular Components in the Built Environment project (AMS/TUD) focused primarily on the shorter cycles of component-renewability: maintenance, reuse/redistribution, and remanufacturing, in order to keep components fit-for-purpose as long as possible [24]. However, longer cycles i.e., recycling trajectories are anticipated through the choice of materials and Design for Disassembly. The project looked at circular service installations (boilers) and kitchens. In particular the latter, circular kitchen, has been elaborated with key stakeholders, that together explored the feasibility to market, whilst developing technical, industrial, and business models. Although the end-user was not directly involved in the project-apart from minor testing with a tenant focus group-lessons learned did address their needs. Most prominently relating the fact that the concept would increase the tenants' freedom of choice, including associated flexibility throughout the use period, since parts of the modular kitchen would come in a range of options. Moreover, the emphasis on market-uptake, rather than on user reflections, was based on the fact that the logistics of product and material circulation should remain the responsibility of the market. The rationale is that this model leads to increased control over the material flows, whilst liberating the resident from any potential burden. This way, more engagement from the user is facilitated, but without stringent obligations.

\section{Derivation of Circ-Flex Criteria}

From the applied mixed-mode methodology, based on literature, case study and expert consultations, three interrelated categories are derived, each comprising of several sub-criteria, leading to a preliminary list of eleven Circ-Flex criteria. Categories and criteria are formulated below and in Table 2.

(1) Flexibility - the extent to which a partition wall, or a part of it, can easily and safely be disassembled, reassembled, repurposed, or disposed of. Specific attention goes to dimensions and-especially—connections, i.e., how elements are fixed,

(2) Circularity - the extent to which walls and wall elements can easily, safely and purely follow high-grade renewability cycles, such as maintenance, redistribution, remanufacturing and recycling, and bio-cascades for biological materials. The main focus is on technical and design anticipation of such cycles i.e., the capacities of stakeholders in the supply chain are left out of the equation, and

(3) User benefits-concerning the mental and behavioral engagement and response that precedes or follows activities by the user. It was found that this user response always has an element of subjectivity, implying that aspects may come to the forefront that overrule solutions chosen 
by designers and engineers. Multiple drivers can be decisive forces in this respect, leading to purchasing behavior that is either in favor of or at the expense of Circ-Flex. For this exercise, two criteria were highlighted in the expert consultations: willingness to engage or invest (in time and money) and freedom of choice, concerning a range of options for materialization, either through DIY or outsourced.

Table 2. Circ-Flex criteria at the crossroads of flexibility, circularity, and user capacity.

\begin{tabular}{cl}
\hline \multicolumn{1}{c}{ CIRC-FLEX CRITERIA } \\
\hline \multirow{3}{*}{ Unlocking Flexibility Capacity } & Ease of Disassembly \\
\cline { 2 - 2 } & Ease of Re-assembly \\
\cline { 2 - 2 } Unlocking User Capacity & Ease of Repurposing or Disposing \\
\cline { 2 - 2 } & User willingness to invest in time and money \\
\hline \multirow{3}{*}{ Unlocking Circularity Capacity } & Ease of Maintenance \\
\cline { 2 - 2 } & Ease of Redistribution \\
\cline { 2 - 2 } & Ease of Recycling \\
\cline { 2 - 2 } & Ease of facilitating Bio-cascades \\
\hline & Ease of facilitating Bio-feedstock \\
\hline
\end{tabular}

\section{Comparative Quick Scan of Two Variants}

Our area of interest is the difference between the performance of a common reference wall and its Circ-Flex counterpart. Of primary concern is the capacity to accommodate change as a quality aspect for the user. This assessment is meant as a first step towards a user-centered method for assessing circular building benefits. Two non-bearing partitioning schemes are compared, following the criteria listed in Table 2. It concerns a non-flexible partitioning configuration and its flexible counterpart. For a fair analysis, we chose schemes of a similar typology, rooted in the residential renovation tradition of the Netherlands. Only the innovative wall scheme introduces clear notions of flexibility and circularity. For the sake of simplicity, we assume that the innovative scheme fits seamlessly and completely into circular models, even if such products may not yet be available on the market. Key here is to compare two wall configurations that at first sight do not differ significantly in aesthetics, functional purpose, and technical specifications for residential settings. The quick scan thus follows basic requirements for a semi-finished partitioning wall. Alongside input from experts and case study, the quick-scan evaluation integrates academic and practical literature on home remodeling and material flows more specifically: [37,67-72].

- Variant I, the reference, is a common timber frame wall with plasterboard panels and mineral wool insulation material. Wires, pipes and insulation can sit within the cavity between the drywall sheets, which cover both sides of the frame. In a finalization step, the wall is plastered. Although such a wall is, in theory, relatively easy to dismantle, it is usually not placed in anticipation of future reuse elsewhere. Nor is it designed, built, and used in a way that tolerates easy replacement without damaging other parts of the housing unit, such as piping, wiring, ceiling, floor, or other walls. This variant is comprised of: a timber frame (European pinewood); fixed with metal connections and screws onto floor and ceiling; glass wool insulation; plasterboard drywall; wooden plinths. Pre-treatment and finishing usually done with traditional products.

- Variant 2 is a partitioning wall built up out of products that are fully designed for circular material and product flow purposes, anticipating existing, proven constructing techniques (not much 
different from variant 1). It comprises of existing elements, as listed in so called Material Passports, such as developed within the Buildings as Material Banks project (BAMB) for example, and/or $\mathrm{C} 2 \mathrm{C}^{\circledR}$ certified products registry $[73,74]$. This way the wall comes as close to a circular wall scheme as possible, knowing that not only the flexibility is anticipated, but also the circularity potential, relating material health and data embeddedness, which in turn accommodates supply and demand cycles at the most optimal rate and utility. The wall scheme comprises a timber frame (European pinewood); fixed with metal connections and screws in framework; using a mounting profile against ceiling and floor; organic fibre insulation; organic board for panelling and plinths. Pre-treatment and finishing done with e.g., pure loam- or lime-based products.

In square meters, there is no difference between the two variants. Furthermore, other specifications are left out of the equation, such as cable and wire content, as they have no relevance for this exploration of criteria for user value. Starting position: post primary installation i.e., the wall is already in place, and layout modifications are considered. Moreover, costs are only obliquely addressed. Table 3 brings together the findings of the quick scan assessment. For the traditional variant, 'down-cycling' ("recycling" into lower grade materials) and 'Incineration and Landfill' are added as possible treatment routes, that are not considered in the Circ-Flex variant.

Table 3. Quick Scan comparison between traditional and Circ-Flex variant.

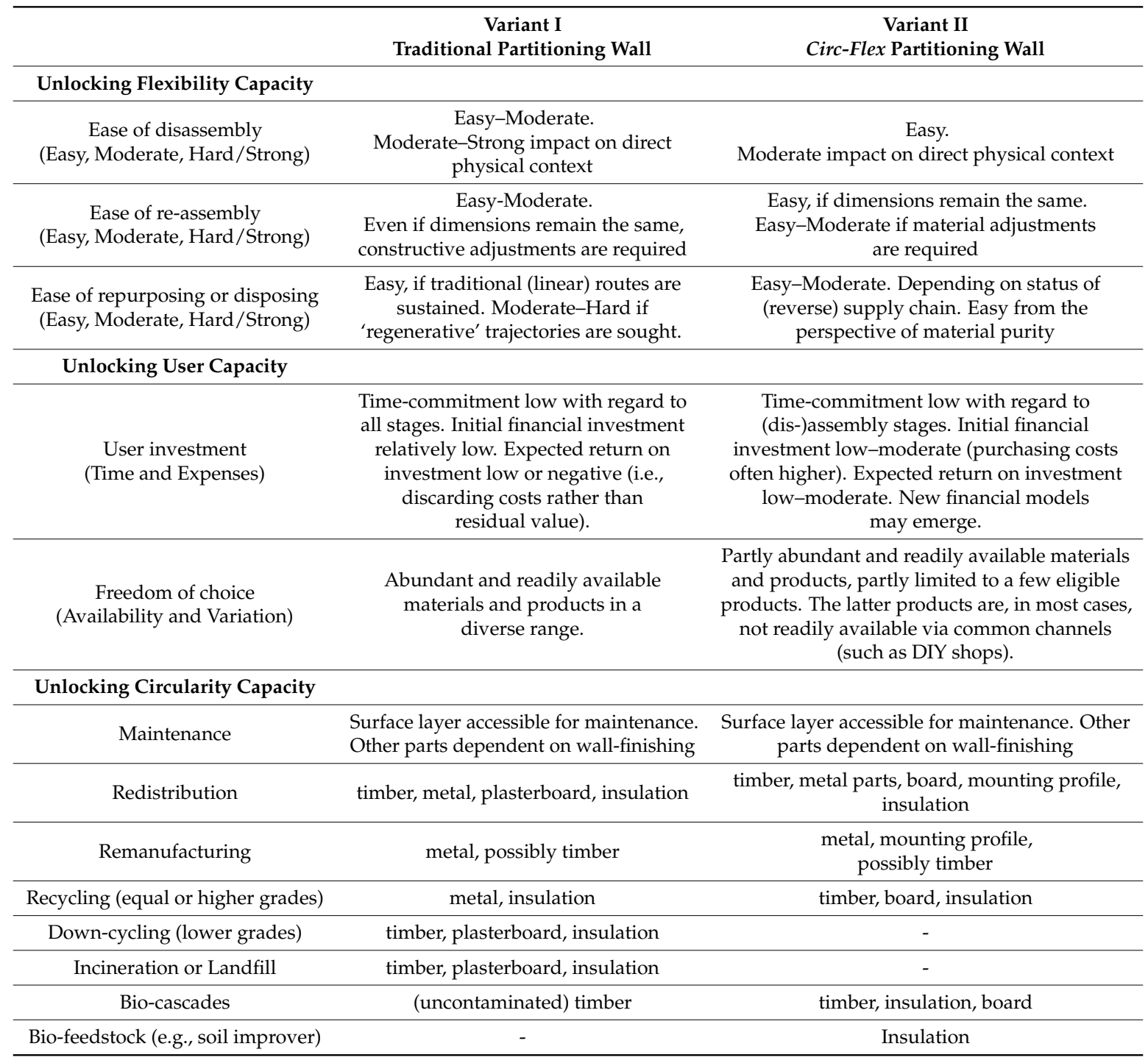




\section{Discussion}

Multiple considerations emerge with regard to the research structure and results, these are addressed below. First, we reflect on the methodological framework. Next, we shed a light on potential constraints in relation to the results, from institutional, legal, cultural, and demographic perspectives.

\subsection{Reflection on Methodology}

The goal of this paper was to introduce user benefits to the circular building discourse and practice in the Netherlands, whilst exploring the relationship with circular and flexible concepts. A literature study revealed a research-gap with regard to the integration of the user, both in building design and building performance evaluation. A study of three cases and expert consultations provided more insight into, the perceived quality of flexible layout configurations, on the one hand, and linkages between user benefits, flexibility, and circularity, on the other. However, the case-study contained only three cases, of a very different nature and period. Moreover, two of those cases were not located in the Netherlands. Conclusions drawn from these insights thus need to be handled with care. Despite those constraints, the findings were valuable enough to extract basic notions on what drives or obstructs residents to modify the layout of their homes. Those basic notions were paired with the input from experts (as well as the literature) in order to select a basic set of criteria. The expert consultations took place in an unstructured way throughout the research trajectory, making it hard to cross-check statements and learning points. Such a heuristic evaluation method has the advantage that it can be executed relatively fast and can allow for unforeseen aspects to come into the picture, deploying a certain experience-based logic. The disadvantage, however, is that in reducing the complexity, some facets may be overlooked. Still, such an approach inherently leads to intersubjective results and a certain level of agreement, provided that the variables are minimized. It was found that the expert consultations provided valuable insights, despite diverging accents in their reflections, which caused a certain bias. These insights either provided decisive conclusions regarding e.g., user engagement and the need for personalization, or they confirmed findings from literature and case study. This may not provide a sound basis for a comprehensive analysis, but was estimated sufficient for a rudimentary set of criteria and quick scan.

An important choice was to keep the two variants as comparable as possible. Current circular building innovation demonstrates a bias towards engineered, modular partitioning concepts, whilst emphasizing design and engineering considerations rather than addressing the average user. Our target, however, is much closer to the latter group. We deemed it justified to assume that average users are more likely to follow known routes and patterns, at least within the foreseeable future, than radically alter their behavior in this respect. This led to notions of accessibility to and familiarity with materials, products as well as the costs. Currently, there is not a large range of products to substitute the traditional ones, whilst facilitating renewability routes, as indicated in Table 3 . But there are certainly several products that apply. Regarding additive-free, recyclable boards or insulation, for example, as well as decorative paint and other coating products. Examples are: Ecor ${ }^{\circledR}$ board (Noble Environmental Technologies), Everuse ${ }^{\circledR}$ insulation (EverUse B.V.), and Graphenstone ${ }^{\circledR}$ paints and mortars (IEdiSA). Some of those come back in the next section concerning institutional, legal and cultural constraints.

Lastly, partitioning flexibility, as an added quality for the user, relates primarily to the relational properties of Figure 3, concerning: performance span of the partitioning, dimensional freedom, and connections that allow easy disassembly. However, it goes without saying that adaptations in partitioning components should never occur at the expense of the quality of intrinsic properties, as indicated in Figure 3 as well. Rather the opposite: flexibility of components accommodates timely upgrades in that respect, think of innovations regarding, for example, thermal comfort control, air purification, VOC reduction, and mold control. 


\subsection{Institutional, Legal, Cultural, and Demographic Context}

The results presented in this paper need further reflection regarding potential constraints. In particular regarding the comparison of two variants. Building paradigms, on the one hand, and lifestyles, on the other, are both culturally and historically determined. As already referred to in the former section, this has an effect on intervention-options and purchasing behavior of the residents. With regard to the housing paradigm in the Netherlands, and the institutional system behind it, one could observe that notions of flexibility have been introduced several times over the last decades, but have not become the norm in this sector. Influenced by "circular ambitions" of decision-makers, resonating in local, national and regional policy documents, new opportunities are emerging. Not least when those ambitions are coupled with demographic trends that impact the housing market, for example relating co-housing and self-organization. However, as yet, the effects are not yet noticeable, let alone measurable. A main challenge in this respect is the acknowledgement of diverging decision-making domains i.e., regarding structural and collective parts of housing, on the one hand, and individual interior parts, on the other. This comprises multiple interrelated-cultural, institutional, and legal—aspects. As long as residents feel not sufficiently incentivized to demand more co-creative power, the building sector does not feel inclined to contest traditional methods, and authorities refrain from implementing legally binding measurements. And vice versa. That said, a change is tangible with regard to purchasing strategies of governments for example. Whether and when this reaches the housing sector remains a question. At this moment, the housing sector faces other challenges that are overruling, sometimes even excluding, notions of circularity and individual user requirements. Such challenges are, for example, the transition towards better energetic performances, and sufficient housing supply, of a sufficient quality, for an increasing demand. The latter is valid for many parts of the Netherlands, not least in the Randstad. Authorities and housing corporations, as well as other investors in the housing stock, have key roles in this respect. A role that comes with the responsibility not to approach challenges in an isolated way, but explore synergies. In that respect, lessons learned in the circular kitchen pilot can be meaningful for other modular concepts for the interior domain as well. This relates to technical, industrial, business, and legal aspects of energy service installations as well as bathrooms and partitioning walls.

In other countries, one could experience forces of a different nature. In Japan, for example, adaptability and flexibility of the housing sector increased massively over the last years, informed by challenges of a decrease in skilled construction workers. As yet, Japan primarily focuses on flexibility and adaptability, and not so much on the link with circular material flows. Moreover, Japan has a completely different housing culture from the Netherlands. It is expected that the results are more valid with regards to other countries where affordable multi-family (social) housing is common, and where there is a certain familiarity with and growing awareness of, both, resilience of the housing stock over time and sustainability challenges of construction materials. One could think of Sweden, Denmark, and the UK for example. That said, we estimate that the results provide valuable insights for formal and informal building industries around the world that are exploring the benefits of CB.

Concerning the applicability of products and innovations that facilitate circularity, there are other related challenges at stake. Related, because it is linked to questions of legal ownership: in the Netherlands, in principle, what is added immovably ("nagelvast") to a dwelling becomes part of the real estate, ownership of which is usually not in the hands of the tenants. That leads to a brief reflection on the implementation of circular partitioning walls. Many innovative products, including those that claim or are proven/certified to be applicable for circular applications, lack the safety standardization of more established products. This is either because standardization lags behind, or simply because the products do not comply with the regulations (yet). Looking at a fiber board product that fits within the variant 2 scheme, for example, shows that fire safety is a main concern. Such products avoid the use of impurities, such as flame retardants, in order to comply with the circularity capacity. That same quality, however, is an obstacle for average use in partitioning configurations, as described in Section 6.1. As soon as the board is fixed, even if that is done in a simple-to-reverse 
way, it is illegal. This reveals a clear conflict in the development potential of partitioning wall products with a strong circular capacity. A freestanding variant, however, could be a solution here, provided it scores sufficiently on other parameters important for the user in question, be it with regard to flexibility capacity, circularity capacity or user capacity. This relates to the observation that, although many criteria of Tables 2 and 3 are relatively well understood, the combination-and even more so: integration - of those criteria are not. This resonates clearly in the category of 'Unlocking user capacities'. For example, time-commitment may increase when high quality repurposing routes are sought but not facilitated through product design or logistics. This blocks the circularity potential. Closely related are financial aspects: innovative financial models, required to facilitate circular value chains, are still underdeveloped [75].

\section{Conclusions}

The underlying hypothesis of this paper was that without tapping into the user domain, circular building cannot reach economies of scale in a sustainable way. The paper was structured around two objectives: (1) further identifying the relationship between flexible and circular building; and (2) exploring the impact of circular, flexible building concepts and practices for the users of multi-family housing regarding interior partitioning. Particular emphasis has been on multi-family housing and the large group of residents that do not have the privilege to act as commissioner or co-developer of their own homes, i.e., lacking the means to create decision power. From the viewpoint of sustainability, this is problematic. In the first place because it disregards users' unique sense of engagement with their living environments. Moreover, it hinders a smooth transfer to a different use of the space due to unforeseen changes. Eleven Circ-Flex criteria, grouped in three categories, were identified as essential for facilitating circular material flows through buildings, in relation to the benefits for residents. The three categories concerned: flexibility capacity, circularity capacity, and user capacity. Together, these criteria extend the circular building discourse to the domain of the user. In a quick-scan assessment, a first grasp was given concerning the differences between a traditional and a Circ-Flex partitioning wall scheme, revealing both opportunities and challenges. Opportunities are associated with the current momentum around CB in the Netherlands, leading to innovations that potentially support user-integration. This concerns product or building design as well as participatory processes. Challenges, on the other hand, are associated with the lack of preconditions for the large scale implementation of such innovations. These concern, for example, reverse logistics and institutional alignment.

Author Contributions: Conceptualization, B.G.; Data curation, B.G.; Formal analysis, B.G.; Investigation, B.G.; Methodology, B.G., M.T. and P.L.; Supervision, M.T. and P.L.

Funding: This research received no external funding.

Conflicts of Interest: The authors declare no conflict of interest.

\section{References}

1. Dutch Ministry of Infrastructure and the Environment, and the Ministry of Economic Affairs. Transitieagenda Circulaire Bouweconomie 2018-2021; Rijksoverheid: The Hague, The Netherlands, 2018.

2. Amsterdam Smart City. Future Perspectives for Amsterdam as a Circular City; Amsterdam Smart City: Amsterdam, The Netherlands, 2018.

3. Giezen, M. Shifting Infrastructure Landscapes in a Circular Economy: An Institutional Work Analysis of the Water and Energy Sector. Sustainability 2018, 10, 3487. [CrossRef]

4. Prendeville, S.; Cherim, E.; Bocken, N. Circular Cities: Mapping Six Cities in Transition. Environ. Innov. Soc. Trans. 2018, 26, 171-194. [CrossRef]

5. Van der Voet, E.; Huele, R.; Koutamanis, A.; van Reijn, B.; van Bueren, E.; Spierings, J.; Demeyer, T.; Roemers, G.; Blok, M. Prospecting the Urban Mine of Amsterdam; Amsterdam Institute for Advanced Metropolitan Solutions: Amsterdam, The Netherlands, 2016. 
6. Geldermans, R.J. Circular Building in the Façade Industry: An Explorative Study into the Social Aspects; VMRG: Nieuwegein, The Netherlands, 2014. (In Dutch)

7. Zuidema, R. Open Building as the basis for Circular Economy Buildings. In Proceedings of the Future of Open Building Conference, Zurich, Switzerland, 9-11 September 2015. [CrossRef]

8. Municipality of Amsterdam, Circle Economy, Fabric, and TNO. Circular Amsterdam-A Vision and Action Agenda for the City and Metropolitan Area; Municipality of Amsterdam: Amsterdam, The Netherlands, 2016.

9. Van der Nagel, A. Naar een circulaire woningvoorraad: Praktijkvoorbeelden van circulair bouwen/slopen/renoveren; Platform31: The Hague, The Netherlands, 2017.

10. Blessing, L.; Chakrabarti, A. DRM, A Design Research Methodology; Springer: Londo, UK, 2009; ISBN 978-1-84882-586-4.

11. Mohmaadi, A.S.M. The Design Process in Architecture-A Pedagogic Approach Using Interactive Thinking. Ph.D. Thesis, School of Civil Engineering, University of Leeds, Leeds, UK, 2001.

12. Attia, S. Regenerative and Positive Impact Architecture—Learning from Case-Studies; Springer: London, UK, 2018; ISBN 9783319667188.

13. Franconi, E.; Bridgeland, B.; Yao, M. Circular business opportunities for the built environment. In $A$ New Dynamic 2-Effective Systems in a Circular Economy; Ellen MacArthur Foundation: Cowes, UK, 2016.

14. De Botton, A. The Architecture of Happiness; Vintage Books: New York, NY, USA, 2006; ISBN 978-0241142486.

15. Schneider, T.; Till, J. Flexible Housing: The means to an end. Arch. Res. Q. 2005, 9, 287-296. [CrossRef]

16. Habraken, N.J. The Use of Levels. Keynote Address Unesco Regional Seminar on Shelter for the Homeless, Seoul 1988; Open House International: Gateshead, UK, 2002; Volume 27, No. 2.

17. Sanoff, H. Multiple views of participatory design. Focus 2011, 8. [CrossRef]

18. Habraken, N.J. De dragers en de mensen-Het einde van de massawoningbouw; Scheltema \& Holkema: Amsterdam, The Netherlands, 1961.

19. Habraken, N.J. The Control of Complexity. Places 1987, 4, 2.

20. Habraken, N.J.; Mignucchi, A.; Teicher, J. Conversations with Form: A Workbook for Students of Architecture; Routledge: Abingdon, UK, 2014.

21. Van der Werf, F. Open Ontwerpen; Uitgeverij 010: Rotterdam, The Netherlands, 1993; ISBN 9064501726.

22. Van der Werf, F. The Molenvliet Project; Open Building Design: Baarn, The Netherlands, 2017.

23. Van Vliet, B.J.M.; de Feijter, F.J. Smart Retrofitting of Urban Housing; Amsterdam Institute for Advanced Metropolitan Solutions: Amsterdam, The Netherlands, 2017.

24. Van Stijn, A.; Gruis, V.; Bortel, G. Circular Components in the Built Environment; Amsterdam Institute for Advanced Metropolitan Solutions: Amsterdam, The Netherlands, 2017.

25. Gruis, V.; Elsinga, M.; Wolters, A.; Priemus, H. Tenant Empowerment through Innovative Tenures: An Analysis of Woonbron-Maasoevers' Client's Choice Programme. Hous. Stud. 2005, 20, 127-147. [CrossRef]

26. Habraken, N.J. SAR Design Method for Housing: Seven Years of Development in the Real World. DMG-DRS J. Des. Res. Methods 1973, 7,3.

27. Habraken, N.J. The Structure of the Ordinary_Form and Control in the Built Environment; Teicher, J., Ed.; MIT Press: New York, NY, USA, 1998; ISBN 0262082608.

28. Boekhorst, F.W.; van der Voort, D.J.M.; Aarts, C.G.; Geraedts, R.P. Enquete aanpasbaar verbouwen; Delft University of Technology: Delft, The Netherlands, 1992.

29. Vreedenburg, E. De bouw uit de knoop; Publikatieburo Bouwkunde; Delft University of Technology: Delft, The Netherlands, 1992.

30. Dekker, K.; Kendall, S. Open Building for Housing Rehabilitation. In Proceedings of the Future Visions of Urban Public Housing, Cincinnati, ON, USA, 17-20 November 1994; pp. 135-145.

31. Van Nunen, H.; Hendriks, N.A. A solution to environmental pressure and housing convenience. In Proceedings of the 9th International Conference on Durability of Building Materials and Components, Brisbane, Australia, 17-21 March 2002.

32. Straub, A.; Vijverberg, G. New strategies for housing quality improvement by Dutch landlords. Open House Int. 2004, 29.

33. Lichtenberg, J.J.N. Slimbouwen, a strategy for product development. In Proceedings of the ARCOM conference, London, UK, 7-9 September 2005. 
34. Leupen, B. The Frame and The Generic Space, A New Way of Looking To Flexibility. In Proceedings of the Open Building and Sustainable Environment Conference, Paris, France, 20-22 September 2004.

35. De Ridder, H.A.J. Living Buildings and the Associated R\&D Based Manufacturers-The Revolution towards Evolutionary Construction. In Proceedings of the International Conference on Management and Innovation for a Sustainable Built Environment, Amsterdam, The Netherlands, 20-23 June 2011.

36. Boelhouwer, P.; Elsinga, M.; Gruis, V.; Priemus, H.; van der Schaar, J.; Thomsen, A. Wonen 6.0, Over de toekomst van de sociale huisvesting in Nederland; Delft University of Technology: Delft, The Netherlands, 2014.

37. Geldermans, R.J.; Rosen-Jacobson, L. Circular Product $\mathcal{E}$ Material Flows in Buildings; Delft University of Technology: Delft, The Netherlands, 2015.

38. Tummers, L. The re-emergence of self-managed co-housing in Europe: A critical review of co-housing research. Urban Stud. 2016, 53, 2023-2040. [CrossRef]

39. Dogge, P.; Smeets, J. In Search of Customer Loyalty-A Research into the Relationship between Tenants' Satisfaction and Commitment. J. Appl. Psychol. 2004, 6, 110-120.

40. Hay, R.; Bradbury, S.; Dixon, D.; Martindale, K.; Samuel, F.; Tait, A. Pathways to POE, Value of Architects; University of Reading: Reading, UK, 2017; ISBN 9780704915718.

41. Hay, R.; Samual, F.; Watson, K.J.; Bradbury, S. Post-occupancy evaluation in architecture: Experiences and perspectives from UK practice. Build. Res. Inf. 2017, 46. [CrossRef]

42. Preiser, W.F.E.; Vischer, J. The evolution of building performance evaluation: An introduction. In Assessing Building Performance; Elsevier: Oxford, UK, 2005; ISBN 0750661747.

43. Visscher, H.J. National and local policies and instruments for energy efficiency of housing in the Netherlands. In Beauty and Energy; Contemporary Ideas for Sustainable New Residential Areas in Europe; Rembarz, G., Ed.; Gdansk University of Technology: Gdansk, Poland, 2009.

44. Whyte, J.; Gann, D.M. Closing the loop between design and use: Post-occupancy evaluation. Build. Res. Inf. 2001, 29, 460-462. [CrossRef]

45. Göçer, O.; Hua, Y.; Göçer, K. Completing the missing link in building design process: Enhancing post-occupancy evaluation method for effective feedback for building performance. Build. Environ. 2015, 89, 14-27. [CrossRef]

46. Kardes, F.; Cronley, M.; Cline, T. Consumer Behavior, 1st ed.; Cengage Learning: Boston, MA, USA, 2011; ISBN 978-1133587675.

47. Kendall, S. An Open Building Strategy for Achieving Dwelling Unit Autonomy in Multi-unit Housing. Hous. Soc. 2004, 1, 89-102. [CrossRef]

48. Durmisevic, E. Dynamic and Circular Buildings by High Transformation and Reuse Capacity. In Proceedings of the Sustainable Innovation Conference on 'Circular Economy' Innovation \& Design, Epsom, Surrey, UK, 7-8 November 2016.

49. Geldermans, R.J. Design for Change and Circularity: Accommodating Circular Material \& Product Flows in Construction. Energy Procedia 2016, 96, 301-311. [CrossRef]

50. Luscuere, P.G.; Geldermans, R.J.; Tenpierik, M.J.; Jansen, S.C. Beyond Sustainability in the Built Environment. Rumoer 2016, 62, 30-49.

51. Brand, S. How Buildings Learn; Viking: New York, NY, USA, 1994; ISBN 9780670835157.

52. Ellen MacArthur Foundation. Towards the Circular Economy-Economic and Business Rationale for an Accelerated Transition; EMF: Cowes, UK, 2012.

53. Dutch Ministry of Infrastructure and the Environment, and the Ministry of Economic Affairs. Nederland Circulair in 2050: Rijksbreed Programma Circulaire Economie; Rijksoverheid: The Hague, The Netherlands, 2016.

54. European Commission. Communication from the Commission to the European Parliament, the Council, the European Economic and Social Committee, and the Committee of the Regions on a Monitoring Framework for the Circular Economy; European Commission: Strasbourg, France, 2018.

55. Gotink, A.K. Evaluatie onderzoek eksperimentele woningbouw project Molenvliet Papendrecht; Faculty of Social and Behavioral Sciences, Utrecht University: Utrecht, The Netherlands, 1978.

56. Li, S. Revisit to Molenvliet Project; Department of Architecture and Building Design, Politecnico di Torino: Turin, Italy, 2014.

57. Minami, K. The efforts to develop longer life housing with adaptability in Japan. Energy Procedia 2016, 96, 662-673. [CrossRef] 
58. Schmidt, R.; Guchi, T.; Austin, S. Lessons from Japan: A look at Century Housing System. In Proceedings of the 12th International Dependency and Structure Modelling Conference, Cambridge, UK, 22-23 July 2010.

59. Wakiyama, Y.; Tsunoda, M.; Matsumura, S. A research on the effectiveness of the century housing system at the early-built CHS houses (in Japanese). AIJ J. Technol. Des. 2000, 6. [CrossRef]

60. Minami, K. The new Japanese housing policy and research and development to promote the longer life of housing. In Proceedings of the Open and Sustainable Buildings Conference, Bilbao, Spain, 17-19 May 2010.

61. Femenias, P.; Holmstrom, C.; Jonsdotter, L.; Thuvanen, L. Architecture, Material Flows, and Climate Impact in Housing; E2B2 C/O; IQ Samhallsbyggnad: Stockholm, Sweden, 2016. (In Swedish)

62. Hand, M.; Shove, E.; Southerton, D. Home extensions in the United Kingdom: Space, time, and practice. Environ. Plan. D Soc. Space 2007, 25, 668-681. [CrossRef]

63. Maller, C.; Horne, R.; Dalton, T. Green renovations, intersections of daily routines, housing aspirations and narratives of environmental sustainability. Hous. Theory Soc. 2012, 29, 255-275. [CrossRef]

64. Alexander, C.; Ishikawa, S.; Silverstein, M. A Pattern Language: Towns-Buildings—Construction; Oxford University Press: Oxford, UK, 1977; ISBN 0195019199.

65. Van der Werf, F.J. Inbouw Innovatie-Een Onderzoek Naar Kwaliteitsaspecten van Inbouwelementen voor de Woningbouw; Stichting Open Bouwen: Rotterdam, The Netherlands, 1987; ISBN 9070284065.

66. Bijdendijk, F.; Aldeliesten, A.T. De wereld van renovatie en transformative—Een staalkaart; Berghauser Pont Publishing: Amsterdam, The Netherlands, 2016; ISBN 9789491930560.

67. Guy, B.; McLendon, S. Building Deconstruction: Reuse and Recycling of Building Materials; Center for Construction and Environment, University of Florida: Gainesville, FL, USA, 2003.

68. Mooallem, J. This Old Recyclable House. Available online: http://www.nytimes.com/2008/09/28/ magazine/28house-t.html (accessed on 23 March 2018).

69. Wallender, L. How to Remove a Full Interior Wall (Non Load-Bearing). Available online: https:/ / www. thespruce.com/removing-full-nonload-bearing-interior-wall-1822875 (accessed on 23 March 2018).

70. Gibson, S. How to Frame a Partition Wall. Available online: https://www.thisoldhouse.com/how-to/howto-frame-partition-wall (accessed on 23 March 2018).

71. Ghyoot, M.; Devlieger, L.; Billiet, L.; Warnier, A. Déconstruction et Réemploi: Comment Faire Circuler Les élements de Construction; Presses polytechniques et universitaires romandes: Lausanne, Switzerland, 2017; ISBN 9782889152391.

72. Rotor Deconstruction. Faire Circuler les Elements de Construction; Pavillon de l'Arsenal: Paris, France, 2018. Available online: http:/ / www.pavillon-arsenal.com/fr/arsenal-tv/conferences/hors-cycle/10949-rotor. html (accessed on 23 March 2018).

73. Luscuere, L. Materials Passports: Optimising value recovery from materials. Proc. Inst. Civ. Eng. Waste Resour. Manag. 2017, 170, 25-28. [CrossRef]

74. $C 2 C^{\circledR}$ Certified Products Registry. Available online: https://www.c2ccertified.org/products/registry (accessed on 23 March 2018).

75. Leising, E.; Quist, J.; Bocken, N. Circular Economy in the building sector: Three cases and a collaboration tool. J. Clean. Prod. 2018, 176, 976-989. [CrossRef]

(C) 2019 by the authors. Licensee MDPI, Basel, Switzerland. This article is an open access article distributed under the terms and conditions of the Creative Commons Attribution (CC BY) license (http://creativecommons.org/licenses/by/4.0/). 